\title{
Incidence and case fatality rate of COVID-19 in patients with active epilepsy
}

\author{
Pablo Cabezudo-García, MD,* Nicolás Lundahl Ciano-Petersen, MD, Natalia Mena-Vázquez, PhD,* \\ Gracia Pons-Pons, MD, María Victoria Castro-Sánchez, MD, and Pedro J. Serrano-Castro, PhD
}

Neurology ${ }^{\circledR}$ 2020;95:e1417-e1425. doi:10.1212/WNL.0000000000010033

\section{Abstract}

\section{Objective}

This article estimates the incidence and fatality of coronavirus disease 2019 (COVID-19) and identifies potential risk factors for fatality in patients with active epilepsy.

\section{Methods}

This is a cross-sectional observational study of patients with active epilepsy and COVID-19. A control group was used to compare the cumulative incidence and case-fatality rate (CFR). The main outcomes of the study were cumulative incidence, defined as number of patients with active epilepsy and COVID-19 admitted to an emergency department divided by the total number of patients with epilepsy at risk, and CFR based on the number of deaths during the enrollment period. Multiple logistic regression analysis was performed to investigate risk factors for fatality in patients with active epilepsy.

\section{Results}

Of the 1,537 patients who fulfilled the inclusion criteria, 21 (1.3\%) had active epilepsy. The cumulative incidence (95\% confidence interval [CI]) of COVID-19 in patients with epilepsy was higher $(1.2 \%[0.6-2.4])$ compared to the population without epilepsy $(0.5 \%[0.5-0.5])$. In reverse transcription PCR-positive patients, there were no significant differences in CFR in patients with active epilepsy compared to patients without epilepsy (33.3\% vs $8.3 \%$; $p=0.266)$. Of the 21 patients with active epilepsy, 5 (23\%) died. In multivariate analysis, the factor associated with fatality in patients with active epilepsy was hypertension (odds ratio [OR] 2.8 [95\% CI 1.3-21.6]). In another model, age (OR 1.0 [95\% CI 1.0-1.1]) and epilepsy (OR 5.1 [95\% CI 1.3-24.0]) were associated with fatality during hospitalization.

\section{Conclusion}

COVID-19 cumulative incidence was higher in patients with active epilepsy. Epilepsy was associated with fatality during hospitalization. Hypertension was associated with fatality in patients with epilepsy.

\author{
Correspondence \\ Dr. Cabezudo-García \\ pablocabezudo@gmail.com
}

\section{MORE ONLINE}

COVID-19 Resources

For the latest articles, invited commentaries, and blogs from physicians around the world NPub.org/COVID19 


\section{Glossary}

ACE2 = angiotensin-converting enzyme 2; AED = antiepileptic drug; AT1 = angiotensin II type 1; CFR = case-fatality rate; CI = confidence interval; COVID-19 = coronavirus disease 2019; HRUM = Hospital Regional Universitario de Málaga; ILAE = International League Against Epilepsy; RT-PCR = reverse transcription PC; SARS-CoV-2 = severe acute respiratory syndrome coronavirus 2 .

The coronavirus disease 2019 (COVID-19) caused by the novel severe acute respiratory syndrome coronavirus 2 (SARSCoV-2) has spread worldwide rapidly as a pandemic. The disease can go unnoticed in asymptomatic infected patients or cause a severe acute respiratory infection that can eventually lead to death. At the time of writing this article, Spain has the world's highest number of deaths per million inhabitants due to COVID-19, as well as the second-highest number of confirmed cases, ${ }^{1,2}$ taking into consideration the variability between countries in the availability and criteria for testing, as well as the rate of false-negatives in reverse transcription PCR (RT-PCR) testing ${ }^{3}$ and the low reliability of serologic tests. ${ }^{4}$

Epilepsy is a disorder characterized by an enduring predisposition of the brain to generate epileptic seizures. ${ }^{5}$ The estimated prevalence of active epilepsy in the world is 6.38 per 1,000 persons $^{6}$; in Spain, it is estimated to be 5.79 per 1,000 persons. ${ }^{7}$ Comorbidities are common in epilepsy, ${ }^{8}$ and some authors propose epilepsy to be considered as an entity that not only consists of the presence of epileptic seizures but also of their comorbidities with a common origin in systemic dysfunction. ${ }^{9}$ Somatic comorbidities are more frequent in patients with epilepsy than in the general population, including cardiovascular risk factors such as diabetes, hypertension, and obesity, ${ }^{10}$ as well as respiratory disorders, especially of infectious origin. ${ }^{11}$ Regarding the latter, patients with epilepsy have a 3-fold increased risk of having pneumonia than the general population and associated with higher mortality rates. ${ }^{12}$ This predisposition may be explained by the risk of aspiration pneumonias during generalized seizures, ${ }^{11}$ but could in addition be related to the underlying cause of the epilepsy (remote symptomatic epilepsies) due to the fact that institutionalized patients have a higher risk of death due to pneumonia and are presumed to be more fragile, and have arduous seizure control and psychomotor retardation, compared with patients with epilepsy in the community. ${ }^{13}$ In addition, pneumonia is a frequent cause of death among pediatric patients with epilepsy, but not in the general pediatric population. ${ }^{13}$ Treatment strategies in epilepsy are deficient in disease-modifying or targeted therapies with some exceptions, ${ }^{14}$ and are mostly based on antiepileptic drugs (AEDs). Those drugs are not only administered for epilepsy and can be useful in a wide spectrum of disorders, although some have been associated with a modest increased risk of infectious diseases. ${ }^{15}$

It remains unknown whether patients with epilepsy have an increased risk of COVID-19 or developing more severe disease. $^{16,17}$ The aim of this study was to determine the incidence and fatality of COVID-19 among patients with active epilepsy compared with the general population, identify the main risk factors related to higher fatality in patients with active epilepsy, and analyze whether epilepsy is associated with fatality in hospitalized patients with COVID-19.

\section{Methods}

\section{Design}

This was a cross-sectional observational study of a case series of patients with active epilepsy. It was conducted in the Instituto de Investigación Biomédica de Málaga and the Neurology Department of Hospital Regional Universitario de Málaga (HRUM), Spain.

\section{Patients}

We included all patients with active epilepsy with admission in the COVID-19 patient flow of HRUM emergencies from March 13 to April 12, 2020 (both included). Eligibility criteria were as follows: at least 14 years old and diagnosis of active epilepsy according to the International League Against Epilepsy (ILAE). ${ }^{18}$ The patients with epilepsy included in this study were diagnosed in the Epilepsy Unit of our service after a standardized diagnostic procedure including, if necessary, long-term video-EEG monitoring and high-resolution MRI. Patients with suspected psychogenic nonepileptic seizures and patients with a final etiologic diagnosis different from COVID-19 were excluded.

To calculate the cumulative incidence and fatality rate in patients with epilepsy, we considered as denominator the extrapolation for the reference area of our hospital of the results of the only population-based epidemiologic study recently carried out in Spain.

\section{Controls}

In order to compare the incidence and fatality of COVID-19 in patients with active epilepsy, we used as a control group all patients 14 years or older without active epilepsy with admission in the COVID-19 patient flow of HRUM. Patients with a final etiologic diagnosis different from COVID-19 were excluded.

We calculated the cumulative incidence and fatality rate of COVID-19 in the global population using the population reference area of our site as the denominator. Public Health Service in Spain includes practically the whole population and during the pandemic the government of Spain decided that both public and private health resources should be directed by a single command. 
Table 1 Cumulative incidence of coronavirus disease 2019 (COVID-19) in patients with active epilepsy and controls

\begin{tabular}{llll}
\hline & No. of patients with COVID-19 & Population at risk $(95 \%$ Cl) & Cumulate incidence $(95 \%$ Cl) \\
\hline No active epilepsy & 1,516 & $300,804(299,348.9-301,708.9)$ & $0.0050(0.0050-0.0050)$ \\
\hline Active epilepsy & 21 & $1,751.7(847.1-3,207.1)$ & $0.0119(0.0065-0.0247)$ \\
\hline No active epilepsy & 511 & Population at risk (95\% Cl) & Cumulate incidence $(95 \%$ Cl) \\
\hline Active epilepsy & 9 & $300,804(299,348.9-301,708.9)$ & $0.0016(0.0016-0.0017)$ \\
\hline
\end{tabular}

Abbreviations: $\mathrm{Cl}=$ confidence interval; $\mathrm{RT}-\mathrm{PCR}=$ reverse transcription $\mathrm{PCR}$

a Population at risk at the beginning of the enrollment period.

\section{Study protocol}

Patients admitted in the COVID-19 patient flow of the HRUM emergency department who met the inclusion and exclusion criteria were selected. The HRUM emergency department COVID-19 patient flow consists of an independent area in the emergency department aimed to evaluate patients with suspected high biological risk. It consists of a consultation room area, a critical care room, and a specific radiology team. All patients with signs or symptoms of acute respiratory infection ${ }^{19}$ according with COVID-19 detected at the triage area were admitted to the COVID-19 patient flow. The patients were subsequently evaluated by a doctor who requested analytical, radiologic, or microbiological tests as well as hospital admission or outpatient management following the recommendations of the Ministry of Health of the Government of Spain. ${ }^{20}$

The patients included in our study were those with a clinical acute respiratory infection compatible with COVID-19, considering Spain a country with community transmission. Following Spanish government valid recommendations in the period of the study, RT-PCR test was performed in patients with moderate to severe disease (i.e., hospitalization required) or in mild cases with any risk factors for a potential COVID19 severe disease. In patients with mild disease and no risk factors, the diagnosis was achieved on clinical grounds. These cases were classified as possible cases according to Spanish government directives. ${ }^{21}$ In all patients who required hospitalization, RT-PCR was performed at least once. Hospitalized patients with a negative RT-PCR but with clinical-radiologic disease compatible with COVID-19 and without finding another etiology were considered as probable cases, also following Spanish government directives. Patients with a positive RT-PCR for SARS-COV-2 were considered COVID-19 confirmed cases.

\section{Standard protocol approvals, registrations, and patient consents}

Data were collected systematically in a predefined sheet from patients' clinical records. Written informed consent was obtained from all patients (or guardians of patients) participating in the study. The study was approved by the local medical ethics committee (Code 0852-N-20).

\section{Study outcomes}

The main outcomes of the study were cumulative incidence and case-fatality rate (CFR). The total cumulative incidence was defined as the number of patients with active epilepsy who met inclusion and exclusion criteria who were admitted to the COVID-19 patient flow during the enrollment period divided by the total number of patients with active epilepsy in the HRUM emergency department health influence area at the start of the enrollment period. The number of patients with active epilepsy at risk at the beginning of the period was estimated based on the total population of 14 years and older served by the HRUM emergency department, which according to the most recent available official epidemiologic reports is 302,556 persons, ${ }^{22-24}$ and on the estimated prevalence of active epilepsy in Spain (5.79 per 1,000 persons; 95\% confidence interval [CI $] 2.8-10.6$ per 1,000 persons). ${ }^{7}$ Cumulative incidence regarding only patients with a positive RT-PCR was also calculated.

The CFR was estimated based on the number of deaths during the enrollment period. Likewise, we calculated CFR for total cases, positive RT-PCR cases, and hospitalized patients.

\section{COVID-19 characteristics outcomes}

Diagnosis of COVID-19 was made based on Spanish Ministry of Health classification, ${ }^{21}$ which considered the following scenarios: confirmed case, applied for patients with a positive RT-PCR for SARS-CoV-2; probable case, applied for patients with a severe acute respiratory infection that required hospitalization with clinical and radiographic features consistent with COVID-19 without RT-PCR confirmation; and possible case, applied for patients with mild acute respiratory infection without RT-PCR confirmation. Other clinical outcomes were pulmonary insufficiency, defined by a basal oxygen saturation $\leq 92 \%$; pneumonia detected on chest $\mathrm{X}$-ray; and requirement of hospitalization. Regarding the laboratory data, the following results were collected: lymphocyte absolute count per $\mathrm{mm}^{3}$, D-dimer, C-reactive protein, ferritin, and lactate dehydrogenase. All treatments for COVID-19 administered were collected: azithromycin, hydroxychloroquine/chloroquine, lopinavir/ritonavir, remdesivir, anti-interleukin-6, anti-interleukin1, steroids, and IV immunoglobulins. 
Table 2 Case-fatality rate of coronavirus disease 2019 (COVID-19) in patients with active epilepsy and controls

\begin{tabular}{llll}
\hline & No. of patients with COVID-19 & No. of deaths & Case-fatality rate $(\boldsymbol{p}<\mathbf{0 . 0 0 1 )}$ \\
\hline No active epilepsy & 1,516 & 55 & 0.036 \\
\hline Active epilepsy & 21 & 5 & 0.238 \\
\hline No active epilepsy & 511 & No. of deaths & Fatality rate $(\boldsymbol{p}=\mathbf{0 . 2 6 6 )}$ \\
\hline Active epilepsy & 9 & 45 & 0.088 \\
\hline & No. of hospitalized patients with COVID-19 & 3 & 0.333 \\
\hline No active epilepsy & 341 & No. of deaths & Case-fatality rate $(\boldsymbol{p}=\mathbf{0 . 0 0 5 )}$ \\
\hline Active epilepsy & 10 & 45 & 0.161 \\
\hline
\end{tabular}

Abbreviation: RT-PCR = reverse transcription PCR.

\section{Other outcomes}

Epidemiologic data were collected including sex, age, dependency (patients admitted to a residential center for disabled people or nursing homes), and institutionalization (patients who need support to perform such basic tasks as dressing, eating, walking, or cleaning), and comorbidities or cardiovascular risk factors including smoking, hypertension, diabetes mellitus, obesity, previous history of heart disease (ischemic heart disease, congestive heart failure, significative arrhythmia), stroke, or pulmonary disease (chronic obstructive pulmonary disease, pulmonary fibrosis, asthma). In regard to epilepsy, active epilepsy was defined as a patient with epilepsy who had seizures in the last 5 years or on treatment with AEDs. Seizure types, epilepsy type, and etiology of the epilepsy according to the ILAE 2017 classification was noted. ${ }^{25,26}$ In addition, data of the AEDs used were collected, including the total number of AEDs used, doses and type of AED, as well as presence of drugresistant epilepsy according to ILAE definition. ${ }^{27}$

\section{Data availability}

Any anonymized data not published within this article will be shared by request from any qualified investigator.

\section{Statistical analysis}

Cumulative incidence of COVID-19 in patients with active epilepsy was estimated and then compared to the estimated cumulative incidence of the patients without active epilepsy. Then we calculated CFR in the epilepsy group and in the control group; $\chi^{2}$ was used to contrast results between groups. Subsequently, a descriptive analysis of patients with active epilepsy was performed. The qualitative variables were expressed as absolute number and their percentage and the quantitative variables as mean (SD) or median (interquartile range) according to their distribution. The adjustment of the normality of the continuous variables was confirmed with the Kolmogorov-Smirnov test. $\chi^{2}$ and Student $t$ or Mann-Whitney $U$ were performed to compare the main characteristics among patients with active epilepsy according to mortality. Finally, a stepwise logistic regression analysis was carried out to explore the variables independently associated with fatality in patients with active epilepsy with COVID-19 infection including into the equation variables that were significant in a previous analysis and of clinical interest. Another logistic regression analysis was performed to identify associated factors. For all analyses, a value of $p<0.05$ was considered significant. All data were analyzed using the statistical program R 2.4-0.

\section{Results}

\section{Cumulative incidence and CFR of COVID-19 in patients with active epilepsy}

A total of 1,572 patients were admitted to the COVID-19 patient flow of the HRUM emergency department between March 13 and April 12, 2020, both days included. A total of 1,537 fulfilled the inclusion and exclusion criteria and enrolled for further analysis. A total of 21 patients (1.3\%) with active epilepsy who met inclusion and exclusion criteria were identified. Table 1 shows the total cumulative incidence of both groups and the cumulative incidence regarding RT-PCRpositive cases only. The cumulative incidence $(95 \% \mathrm{CI})$ of COVID-19 in patients with active epilepsy was higher $(1.2 \%$ [0.6-2.4]) compared to population without active epilepsy $(0.5 \%[0.5-0.5])$. The cumulative incidence in patients with epilepsy was also higher considering only the patients with positive RT-PCR $(0.5 \%[0.2-1.0]$ vs $0.1 \%[0.1-0.1])$.

Table 2 shows CFR results. The total CFR was higher in patients with active epilepsy compared to patients without active epilepsy $(23.8 \%$ vs $3.6 \% ; p<0.001)$ and considering only hospitalized patients $(50.0 \%$ vs $16.1 \%$; $p=0.005)$. These differences were also observed taking into account only patients with positive RT-PCR, although these differences did not reach statistical significance $(33.3 \%$ vs $8.8 \%$; $p=0.266$ ).

\section{Characteristics and factors associated with fatality in hospitalized patients with COVID-19} Of the 351 hospitalized patients, 60 (17.1\%) died. Most of the hospitalized patients were male $(60.1 \%)$ with an approximated 
Table 3 Single and multiple logistic regression results for coronavirus disease 2019 (COVID-19) case fatality in hospitalized patients

\begin{tabular}{llll}
\hline Variable & Univariate OR $(95 \% \mathrm{Cl})$ & Multivariate ${ }^{\mathrm{a}}$ OR $(95 \% \mathrm{Cl})$ & $\boldsymbol{p}$ Value \\
\hline Age, $\mathbf{y}$ & $1.07(1.04-1.09)$ & $1.07(1.04-1.09)$ & \\
\hline Sex, male & $1.39(0.79-2.44)$ & $5.12(1.39-24.09)$ & 0.016 \\
\hline Epilepsy & $5.20(1.45-18.56)$ & \\
\hline Hypertension & $2.96(1.561-5.62)$ & \\
\hline Diabetes mellitus & $1.54(0.85-2.81)$ & \\
\hline Heart disease & $2.48(1.38-4.46)$ & \\
\hline Pulmonary disease & $1.58(0.85-2.95)$ & \\
\hline
\end{tabular}

Abbreviations: $\mathrm{Cl}$ = confidence interval; $\mathrm{OR}=$ odds ratio.

All the variables shown in the table were included in the equation.

a Naglerke $R^{2}=0.183$.

mean age of 67 years. More than half were hypertensive (56.7\%). Other comorbidities were diabetes (23.6\%), heart disease $(25.4 \%)$, and chronic pulmonary disease (22.5\%). A total of 32/351 received invasive mechanical ventilation; one of them was a patient with epilepsy. At the final study date, 103 patients without epilepsy and 3 with active epilepsy were still hospitalized.

A total of 10/351 (2.8\%) were patients with epilepsy, 8/10 (80\%) were dependent, and 7/10 (70\%) were hypertensive. Fatality in hospitalized patients was associated with age, epilepsy, hypertension, and heart disease. The results of the multivariate analysis in table 3 show that CFR in hospitalized patients with COVID-19 was associated with age and presence of active epilepsy.

\section{Sociodemographic characteristics and clinical features of patients with active epilepsy and COVID-19}

The main characteristics and clinical features of patients with active epilepsy and COVID-19 are shown in table 4. Most patients were male $(67 \%)$ with an approximate mean age of 58 years. More than half were in a dependent situation and one-third were institutionalized. Hypertension was the most frequent comorbidity, followed by other cardiovascular risk factors. Most patients had focal epilepsy (57\%), with structural etiology being the most frequent (33\%; vascular $n=1$, meningioma $n=2$, malignancy $n=$ 2 , dysplasia $\mathrm{n}=1$, and degenerative $\mathrm{n}=1$ ). More than half had presented generalized tonic-clonic seizures. In 2 patients, the type of seizure and the type of epilepsy was unknown. All patients were on AEDs and levetiracetam was the most commonly used. A third of the patients were on treatment with 2 or more AEDs and only one patient had drug-resistant epilepsy.

Nine patients (42.9\%) were confirmed, 5 (23.8\%) probable, and $7(33.3 \%)$ possible cases. Almost half of the patients (43\%) required hospitalization and 5/21 (23\%) died. Two patients had epileptic seizures during the course of the disease. One patient had arrhythmia, but none had QT lengthening. Most had radiologic pneumonia (85\%). The analytical characteristics are shown in table 3. Regarding treatment, all patients received some treatment for COVID-19 and the most commonly used treatment was azithromycin followed by glucocorticoids.

\section{Factors associated with COVID-19 fatality in patients with active epilepsy}

Of the 21 patients with active epilepsy, 5 (23\%) died. Patients who died had a higher mean age and higher frequency of hypertension and diabetes mellitus. There were no differences in epilepsy characteristics. Most patients who died were on treatment with valproate $(60 \%)$ but no statistical significance was found compared with alive patients $(p=0.075)$. Radiologic pneumonia was common in both groups. There were no differences in analytical characteristics or treatment for COVID-19 between the groups.

Table 5 shows the logistic regression multivariate analysis (dependent variable: fatality) in patients with epilepsy with COVID19. The presence of hypertension was independently associated with fatality in patients with epilepsy with COVID-19.

\section{Discussion}

The pandemic caused by SARS-CoV-2 that originated in Wuhan, China, ${ }^{25}$ has affected most countries worldwide, including Spain. The disease can go unnoticed in some patients or otherwise cause a severe acute respiratory infection that can eventually lead to death. Several risk factors have been proved to be associated with more severe disease, including advanced age, heart disease, hypertension, diabetes mellitus, chronic pulmonary disease, obesity, and cancer. ${ }^{26-28}$ The Centers for Disease Control and Prevention have suggested that some neurologic diseases such as epilepsy might be a risk factor for COVID-19, partly due to the increased rate of comorbidities associated with these patients. ${ }^{16}$ Because there is very limited evidence of COVID-19 in patients with 
Table 4 Characteristics of patients with active epilepsy and coronavirus disease 2019 (COVID-19)

\begin{tabular}{|c|c|}
\hline Variable & $\begin{array}{l}\text { Active epilepsy } \\
(\mathrm{n}=21)\end{array}$ \\
\hline \multicolumn{2}{|l|}{ Epidemiologic features } \\
\hline Age, y & $57.8(17.0)$ \\
\hline Sex, male & $14(66.7)$ \\
\hline Institutionalized $^{a}$ & 7 (33.3) \\
\hline Dependent $^{\mathbf{b}}$ & $13(61.9)$ \\
\hline \multicolumn{2}{|l|}{ Comorbidities } \\
\hline Obesity & $6(28.6)$ \\
\hline Hypertension & 7 (33.3) \\
\hline ACE inhibitors & $3(14.3)$ \\
\hline $\begin{array}{l}\text { Angiotensin II type } 1 \text { receptor } \\
\text { antagonists }\end{array}$ & $4(19.0)$ \\
\hline Diabetes mellitus & $5(23.8)$ \\
\hline Smoking & $4(19.0)$ \\
\hline Heart disease & $5(23.8)$ \\
\hline Pulmonary disease & $4(19.0)$ \\
\hline Stroke & $2(9.5)$ \\
\hline
\end{tabular}

\section{Clinical features of epilepsy}

Type of epilepsy

\begin{tabular}{|c|c|}
\hline Focal & $12(57.1)$ \\
\hline Generalized & $2(9.5)$ \\
\hline Unknown & $7(33.3)$ \\
\hline \multicolumn{2}{|l|}{ Etiology } \\
\hline Structural & $7(33.3)$ \\
\hline Genetic & $2(9.5)$ \\
\hline Infectious & $0(0.0)$ \\
\hline Metabolic & $0(0.0)$ \\
\hline Immune & $0(0.0)$ \\
\hline Unknown & $11(52.4)$ \\
\hline \multicolumn{2}{|l|}{ COVID-19 diagnosis } \\
\hline Possible & $7(33.3)$ \\
\hline Probable & $5(23.8)$ \\
\hline Confirmed & $9(42.9)$ \\
\hline \multicolumn{2}{|l|}{ Clinical features } \\
\hline Hospitalization & $9(42.9)$ \\
\hline Respiratory insufficiency & $10(47.6)$ \\
\hline Epileptic seizures during the infection & $2(9.5)$ \\
\hline Arrhythmia & $1(4.8)$ \\
\hline
\end{tabular}

Table 4 Characteristics of patients with active epilepsy and coronavirus disease 2019 (COVID-19) (continued)

\begin{tabular}{ll}
\hline Variable & $\begin{array}{l}\text { Active epilepsy } \\
(\mathbf{n}=\mathbf{2 1})\end{array}$ \\
\hline Prolonged QT & $0(0.0)$ \\
\hline Deaths & $5(23.8)$ \\
\hline Radiologic features & $18(85.7)$ \\
\hline Radiologic signs of pneumonia & \\
\hline Laboratory features & $54.0(5.0-156.2)$ \\
\hline CRP, mg/dL & $1,700.0(900.0-2,795.0)$ \\
\hline Lymphocytes per mm ${ }^{3}$ & $1,148.5(480.0-2,007.2)$ \\
\hline D-dimer, Hg/L & $192.0(152.0-277.0)$ \\
\hline LDH & $97.0(38.0-118.0)$ \\
\hline Ferritin & \\
\hline Treatment & $11(52.4)$ \\
\hline Azithromycin & $4(19.0)$ \\
\hline Cefditoren & $5(23.8)$ \\
\hline Lopinavir/ritonavir & $5(23.8)$ \\
\hline Hydroxychloroquine/chloroquine & $0(0.0)$ \\
\hline IL-6 inhibitors & $7(33.3)$ \\
\hline Steroids & \\
\hline & \\
\hline
\end{tabular}

Abbreviations: $\mathrm{ACE}=$ angiotensin-converting enzyme; $\mathrm{CRP}=\mathrm{C}$-reactive protein; IL = interleukin; IQR = interquartile range; $L D H=$ lactate dehydrogenase.

a Institutionalized $=$ admitted to a residential center for disabled people or nursing home.

${ }^{\mathrm{b}}$ Dependent $=$ needs support to perform such basic tasks as dressing, eating, walking, or cleaning.

epilepsy, we conducted this study to determine the incidence and fatality rate of this disease in patients with active epilepsy, as well as potential risk factors that could be associated with fatality. We also studied active epilepsy as a possible risk factor for fatality in hospitalized patients with COVID-19.

In our study, we observed a higher cumulative incidence of COVID-19 in patients with active epilepsy than in patients without epilepsy. The fact that we included all cases whether they were confirmed, probable, or possible could be considered an asset as potential false-negatives have not been misplaced. ${ }^{3}$ Nevertheless, we also obtained a higher incidence considering only confirmed cases by positive RT-PCR. These results should be considered in the context of the high rates of asymptomatic patients with COVID-19 reported in the literature. ${ }^{29}$ Young age is the only factor found to be associated with an asymptomatic course. ${ }^{30}$ However, there are risk factors associated with more severe disease that are more prevalent in patients with epilepsy, ${ }^{10,11}$ which could explain the higher incidence of COVID-19 among people with epilepsy. 
Table 5 Single and multiple logistic regression results for coronavirus disease 2019 case fatality in patients with active epilepsy

\begin{tabular}{lll}
\hline Variable & Univariate OR $(95 \% \mathrm{Cl})$ & Multivariate ${ }^{\mathrm{a}}$ OR $(95 \% \mathrm{Cl})$ \\
\hline Age, $\mathbf{y}$ & $1.08(1.01-1.17)$ & $\boldsymbol{p}$ Value \\
\hline Sex, male & $1.46(0.18-11.71)$ & $2.85(1.37-21.60)$ \\
\hline Obesity & $1.87(0.73-17.8)$ & \\
\hline Hypertension & $2.85(1.38-21.60)$ & \\
\hline Diabetes mellitus & $2.35(1.02-17.16)$ & \\
\hline Heart disease & $1.06(0.32-25.70)$ & \\
\hline Pulmonary disease & $1.54(0.45-27.62)$ & \\
\hline
\end{tabular}

Abbreviations: $\mathrm{Cl}=$ confidence interval; $\mathrm{OR}=$ odds ratio.

The variables included in the equation were age, hypertension, and diabetes.

a Naglerke $R^{2}=0.212$.

There is variability in the CFRs reported in different populations. For instance, China has reported a $2.3 \%$ mortality rate and Italy a $7.2 \%$ mortality rate. ${ }^{31}$ In Spain, the calculated CFR in confirmed cases with the last data available from the Spanish Ministry of Health at the time of writing this article is $11.2 \%{ }^{32}$ These differences from countries like China could be explained by a higher mean age of the population, higher rates of comorbidities, and tendency of not testing patients with mild symptoms or asymptomatic exposed patients. ${ }^{31}$ The CFR of all the confirmed cases in our study is $9.2 \%$, similar to the estimations made by the Spanish Ministry of Health. In our study, the CFR was higher in patients with active epilepsy than in the control group. This result could be explained by the higher rate of risk factors for a severe form of COVID-19 in patients with epilepsy, such as hypertension. ${ }^{26-28,33}$ In fact, in our study, hypertension was the only independent risk factor associated with fatality in patients with epilepsy. However, we could not find significant differences in patients with positive RT-PCR. Spanish government directives during the period of our study recommended performing RT-PCR only in patients with moderate to severe disease (i.e., hospitalization required) or patients with mild symptoms but considered vulnerable (i.e., patients with epilepsy) for risk of developing severe disease. According to this, a higher proportion of patients with moderate to severe disease or considered vulnerable should be expected to be found in the RT-PCR-positive group of patients without epilepsy with respect to the total population and thus to have a higher fatality rate. This higher proportional increase of fatality rate in the group of patients without epilepsy and the small sample of patients in the patients with epilepsy group could explain the lack of significance.

In the multivariate analysis in hospitalized patients, risk factors associated independently with fatality were age and epilepsy. This could be explained by the vulnerability of the hospitalized patients with epilepsy with high comorbidity burden such as hypertension. The multivariate analysis showed that in patients with active epilepsy, hypertension was independently associated with fatality. The fact that hypertension was not an independent factor for fatality in hospitalized patients can be explained because more than half of them were hypertensive.

Some recent studies have reported hypertension as the most common comorbidity associated with COVID- $19 .{ }^{26}$ However, the role of hypertension and its treatments is unclear. ${ }^{34}$ An overexpression of the angiotensin-converting enzyme 2 (ACE2) in patients treated with ACE2 inhibitors or angiotensin II type 1 (AT1) receptor antagonists ${ }^{35}$ have been proposed. In our cohort, all patients were on ACE2 inhibitors or AT1 receptor antagonists; no differences in mortality were found regarding those treatments.

Our study has several limitations. Our cohort group has a small sample size. Nevertheless, we found risk factors associated with higher fatality rates in patients with epilepsy with COVID-19 that had previously been reported in general population studies. Although we had a large control group to estimate cumulative incidence and CFR in the general population, we only have whole data of those hospitalized. Another fact to consider is that we included patients without confirmation by RT-PCR as COVID-19 cases; this may have caused the inclusion in the study of some patients without COVID-19. However, to reduce this bias, we ruled out those patients with a confirmed etiologic diagnosis other than COVID-19. Finally, in any hospitalbased study, we must consider that the chance of admission is modified by a risk factor of interest. In this case, the probability of being admitted (including going to the hospital) when one has COVID-19 symptoms is greater if one also has other illnesses (perhaps epilepsy). This fact may have had an influence on our results, although it does not detract from their validity.

The incidence of COVID-19 is higher in patients with active epilepsy than in the general population. This could be 
explained by higher risk of presenting symptoms and higher number of RT-PCR tests performed in vulnerable patients with higher comorbidities burden related to the severity of COVID-19, as occurs in patients with epilepsy. Epilepsy could be an independent risk factor for fatality in hospitalized patients with COVID-19. Hypertension could be an independent factor for fatality in patients with active epilepsy. These data should be corroborated with future studies with a larger number of patients with active epilepsy and COVID19 to confirm our results as well as to identify other possible risk factors related to the severity of COVID-19 in patients with active epilepsy.

\section{Acknowledgment}

The authors thank the staff of Hospital Regional Universitario de Málaga for attending patients with COVID-19, including specialists in infectious diseases, preventive medicine, microbiology, emergency services, intensive care, and pneumology.

\section{Study funding}

Grant provided for medical researchers by the "Fundación Española de Reumatología.”

\section{Disclosure}

Pablo Cabezudo-García reports speaking fees from EISAI, BIAL, UCB, Esteve, Neuraxpharm, and Exeltis. Nicolás Lundhal Ciano-Petersen reports no disclosures relevant to the manuscript. Natalia Mena-Vazquez reports speaking fees from Novartis, Pfizer, AbbVie, UCB, and Roche. Gracia PonsPons and María Victoria Castro-Sánchez report no disclosures relevant to the manuscript. Pedro J. Serrano Castro reports speaking fees from EISAI, BIAL, UCB, Esteve, Neuraxpharm, and Exeltis. Go to Neurology.org/N for full disclosures.

\section{Publication history}

Received by Neurology April 30, 2020. Accepted in final form June 1, 2020.

Appendix Authors

\begin{tabular}{|c|c|c|}
\hline Name & Location & Contribution \\
\hline $\begin{array}{l}\text { Pablo } \\
\text { Cabezudo- } \\
\text { García, MD }\end{array}$ & $\begin{array}{l}\text { Hospital Regional } \\
\text { Universitario de } \\
\text { Málaga, Spain }\end{array}$ & $\begin{array}{l}\text { Major role in design and } \\
\text { conceptualization of the study; } \\
\text { major role in the acquisition } \\
\text { and interpretation of data; } \\
\text { major role in drafting and } \\
\text { revising the manuscript for } \\
\text { intellectual content }\end{array}$ \\
\hline
\end{tabular}

\begin{tabular}{lll}
\hline $\begin{array}{l}\text { Nicolás } \\
\text { Lundahl Ciano- } \\
\text { Petersen, MD }\end{array}$ & $\begin{array}{l}\text { Hospital Regional } \\
\text { Universitario de } \\
\text { Málaga, Spain }\end{array}$ & $\begin{array}{l}\text { Major role in the acquisition of } \\
\text { data; major role in drafting and } \\
\text { revising the manuscript for } \\
\text { intellectual content }\end{array}$ \\
\hline $\begin{array}{l}\text { Natalia Mena- } \\
\text { Vázquez, PhD }\end{array}$ & $\begin{array}{l}\text { Hospital Regional } \\
\text { Universitario de } \\
\text { Málaga, Spain }\end{array}$ & $\begin{array}{l}\text { Major role in design and } \\
\text { conceptualization of the study; } \\
\text { major role in the analysis of the } \\
\text { data; major role in drafting and } \\
\text { revising the manuscript for } \\
\text { intellectual content }\end{array}$ \\
\hline
\end{tabular}

Appendix (continued)

\begin{tabular}{lll}
\hline Name & Location & Contribution \\
\hline $\begin{array}{l}\text { Gracia Pons- } \\
\text { Pons, MD }\end{array}$ & $\begin{array}{l}\text { Hospital Regional } \\
\text { Universitario de } \\
\text { Málaga, Spain }\end{array}$ & $\begin{array}{l}\text { Major role in the acquisition of } \\
\text { data }\end{array}$ \\
\hline $\begin{array}{l}\text { María Victoria } \\
\text { Castro- } \\
\text { Sánchez, MD }\end{array}$ & $\begin{array}{l}\text { Hospital Regional } \\
\text { Universitario de }\end{array}$ & $\begin{array}{l}\text { Major role in the acquisition of } \\
\text { data }\end{array}$ \\
$\begin{array}{l}\text { Pedro J. } \\
\text { Serrano- } \\
\text { Castro, PhD }\end{array}$ & $\begin{array}{l}\text { Hospital Regional } \\
\text { Universitario de } \\
\text { Málaga, Spain }\end{array}$ & $\begin{array}{l}\text { Major role in drafting and } \\
\text { revising the manuscript for } \\
\text { intellectual content }\end{array}$ \\
\hline
\end{tabular}

\section{References}

1. European Centre for Disease Prevention and Control. COVID-19 situation update worldwide, as of 24 April 2020. 2020. Available at: ecdc.europa.eu/en/geographicaldistribution-2019-ncov-cases. Accessed April 24, 2020.

2.@OurWorldInData. Daily and total confirmed COVID-19 deaths per million: @OurWorldInData. 2020. Available at: ourworldindata.org/grapher/total-dailycovid-deaths-per-million. Accessed April 25, 2020.

3. Li Y, Yao L, Li J, et al. Stability issues of RT-PCR testing of SARS-CoV-2 for hospitalized patients clinically diagnosed with COVID-19. J Med Virol Epub 2020 Mar 26.

4. World Health Organization. Advice on the use of point-of-care immunodiagnostic tests for COVID-19. Geneva: World Health Organization; 2020.

5. Fisher RS, Acevedo C, Arzimanoglou A, et al. ILAE official report: a practical clinical definition of epilepsy. Epilepsia 2014;55:475-482.

6. Fiest KM, Sauro KM, Wiebe S, et al. Prevalence and incidence of epilepsy: a systematic review and meta-analysis of international studies. Neurology 2017;88:296-303.

7. Serrano-Castro PJ, Mauri-Llerda JA, Hernandez-Ramos FJ, et al. Adult prevalence of epilepsy in Spain: EPIBERIA, a population-based study. ScientificWorldJournal 2015; 2015:602710.

8. Keezer MR, Sisodiya SM, Sander JW. Comorbidities of epilepsy: current concepts and future perspectives. Lancet Neurol 2016;15:106-115.

9. Yuen AWC, Keezer MR, Sander JW. Epilepsy is a neurological and a systemic disorder. Epilepsy Behav 2018;78:57-61.

10. Comorbidity in adults with epilepsy: United States, 2010. MMWR Morb Mortal Wkly Rep 2013;62:849-853.

11. Gaitatzis A, Sisodiya SM, Sander JW. The somatic comorbidity of epilepsy: a weighty but often unrecognized burden. Epilepsia 2012;53:1282-1293.

12. Gaitatzis A, Carroll K, Majeed A, Sander JW. The epidemiology of the comorbidity of epilepsy in the general population. Epilepsia 2004;45:1613-1622.

13. Gaitatzis A, Sander JW. The mortality of epilepsy revisited. Epileptic Disord 2004;6:3-13.

14. Kearney H, Byrne S, Cavalleri GL, et al. Tackling epilepsy with high-definition precision medicine: a review. JAMA Neurol 2019;76:1109-1116.

15. Zaccara G, Giovannelli F, Giorgi FS, Franco V, Gasparini S, Tacconi FM. Do antiepileptic drugs increase the risk of infectious diseases? A meta-analysis of placebocontrolled studies. Br J Clin Pharmacol 2017;83:1873-1879.

16. Kuroda N. Epilepsy and COVID-19: associations and important considerations. Epilepsy Behav 2020:107122.

17. French JA, Brodie MJ, Caraballo R, et al. Keeping people with epilepsy safe during the COVID-19 pandemic. Neurology 2020;94:1032-1037.

18. Commission on Epidemiology and Prognosis, International League Against Epilepsy. Guidelines for epidemiologic studies on epilepsy.Epilepsia 1993;34:592-596.

19. World Health Organization. Global surveillance for COVID-19 caused by human infection with COVID-19 virus: interim guidance, 20 March 2020. Geneva: World Health Organization; 2020.

20. Ministerio de Sanidad, Consumo y Bienestar Social. Información científico-técnica, enfermedad por coronavirus, COVID-19. Madrid: Ministerio de Sanidad, Consumo y Bienestar Social; 2020.

21. Ministerio de Sanidad, Consumo y Bienestar Social. Procedimiento de actuación frente a casos de infección por el nuevo Coronavirus (SARS-CoV-2). Madrid: Ministerio de Sanidad, Consumo y Bienestar Social; 2020.

22. Ayuntamiento de Málaga: Organismo Autónomo de Gestión Tributaria. Estadísticas población 2019: población por grupos de edad 2019. Available at: gestrisam.malaga. eu/export/sites/default/economia/gestrisam/portal/menu/portada/documentos/ 2019 Poblacixn por grupos de edad.pdf. Accessed April 25, 2020.

23. Ayuntamiento Rincón de la Victoria. Estadísticas de población a 30 de Septiembre de 2019. Available at: rincondelavictoria.es/poblacion-y-estadistica/cat/estadisticas-depoblacion. Accessed April 25, 2020.

24. Instituto de Estadística y Cartografía de Andalucía, Consejería de Economía, Conocimento, Empresas y Universidad. Instituto de Estadística y Cartografía de Andalucía. 2020. Available at: juntadeandalucia.es/institutodeestadisticaycartografia/. Accessed April 25, 2020.

25. Liang WH, Guan WJ, Li CC, et al. Clinical characteristics and outcomes of hospitalised patients with COVID-19 treated in Hubei (epicenter) and outside Hubei (non-epicenter): a nationwide analysis of China. Eur Respir J 2020;55:2000562. 
Zhou F, Yu T, Du R, et al. Clinical course and risk factors for mortality of adult inpatients with COVID-19 in Wuhan, China: a retrospective cohort study. Lancet 2020;395:1054-1062.

27. Wu Z, McGoogan JM. Characteristics of and important lessons from the coronavirus disease 2019 (COVID-19) outbreak in China: summary of a report of 72314 cases from the Chinese Center for Disease Control and Prevention. JAMA 2020;323: $1239-1242$.

28. Preliminary estimates of the prevalence of selected underlying health conditions among patients with coronavirus disease 2019: United States, February 12-March 28, 2020. MMWR Morb Mortal Wkly Rep 2020;69:382-386.

29. Mizumoto K, Kagaya K, Zarebski A, Chowell G. Estimating the asymptomatic proportion of coronavirus disease 2019 (COVID-19) cases on board the Diamond Princess cruise ship, Yokohama, Japan, 2020. Euro Surveill 2020;25:2000180.
30. Hu Z, Song C, Xu C, et al. Clinical characteristics of 24 asymptomatic infections with COVID-19 screened among close contacts in Nanjing, China. Sci China Life Sci 2020; 63:706-711.

31. Onder G, Rezza G, Brusaferro S. Case-fatality rate and characteristics of patients dying in relation to COVID-19 in Italy. JAMA 2020;323:1775-1776.

32. Centro Nacional de Epidemiología. Situación de COVID-19 en España. 2020. Available at: covid19.isciii.es/. Accessed April 22, 2020.

33. Li X, Xu S, Yu M, et al. Risk factors for severity and mortality in adult COVID-19 inpatients in Wuhan. J Allergy Clin Immunol Epub 2020 Apr 12.

34. Schiffrin EL, Flack J, Ito S, Muntner P, Webb C. Hypertension and COVID-19. Am J Hypertens Epub 2020 Apr 6.

35. Fang L, Karakiulakis G, Roth M. Are patients with hypertension and diabetes mellitus at increased risk for COVID-19 infection? Lancet Respir Med 2020;8:e21. 


\section{Neurology}

Incidence and case fatality rate of COVID-19 in patients with active epilepsy

Pablo Cabezudo-García, Nicolás Lundahl Ciano-Petersen, Natalia Mena-Vázquez, et al. Neurology 2020;95; e1417-e1425 Published Online before print June 17, 2020

DOI 10.1212/WNL.0000000000010033

This information is current as of June 17, 2020

\section{Updated Information \&} Services

References

Citations

Subspecialty Collections

Permissions \& Licensing

Reprints including high resolution figures, can be found at: http://n.neurology.org/content/95/10/e1417.full

This article cites 21 articles, 2 of which you can access for free at: http://n.neurology.org/content/95/10/e1417.full\#ref-list-1

This article has been cited by 1 HighWire-hosted articles: http://n.neurology.org/content/95/10/e1417.full\#\#otherarticles

This article, along with others on similar topics, appears in the following collection(s):

All epidemiology

http://n.neurology.org/cgi/collection/all_epidemiology

All Epilepsy/Seizures

http://n.neurology.org/cgi/collection/all_epilepsy_seizures

Information about reproducing this article in parts (figures,tables) or in its entirety can be found online at:

http://www.neurology.org/about/about_the_journal\#permissions

Information about ordering reprints can be found online:

http://n.neurology.org/subscribers/advertise

Neurology ${ }^{\circledR}$ is the official journal of the American Academy of Neurology. Published continuously since 1951, it is now a weekly with 48 issues per year. Copyright () 2020 American Academy of Neurology. All rights reserved. Print ISSN: 0028-3878. Online ISSN: 1526-632X.

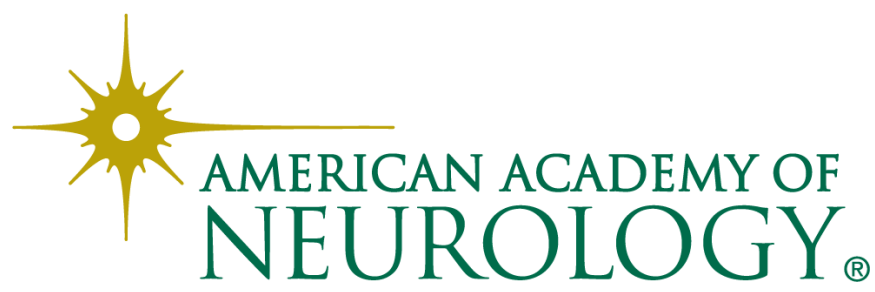

